\title{
Reabilitação vestibular na criança: estudo preliminar
}

\section{Vestibular rehabilitation in children: preliminary study}

Roseli S. M. Bittari', Maria E. B. Pedalini' ${ }^{2}$ Ítalo R. T.
Medeiros ${ }^{3}$, Marco A. Bottino $^{1}$, Ricardo F. Bento $^{4}$

Resumo / Summary

$\mathbf{F}$

orma de estudo: Clínico prospectivo. Objetivo: 0 estudo analisa prospectivamente os resultados da Reabilitação Vestibular pelo método de Cawtorne \& Cooksey em 22 crianças, portadoras de vestibulopatia periférica, associada ou não a sintomas centrais, com idade média de 8,6 anos. Material e método: Os exames quantitativos da função vestibular utilizados para quantificar a vestibulopatia foram a eletronistagmografia e a prova rotatória pendular decrescente (PRPD), mas a história clínica altamente sugestiva de processo vestibular foi considerada diagnóstica mesmo na presença de exames normais. Resultado: Os resultados apontam a Reabilitação Vestibular como uma opção válida no tratamento das vestibulopatias na infância, uma vez que não houve casos não responsivos ao tratamento.
Palavras-chave: reabilitação vestibular, vertigem, criança. Key words: Vestibular rehabilitation, dizziness, child.

${ }^{1}$ Doutor do Setor de O toneurologia.

${ }^{2}$ Fonoaudióloga responsável pelo ambulatório de Reabilitação Vestibular, mestranda do Curso de Pós-Graduação da Fisopatologia Experimental da FMUSP.

${ }^{3}$ Pós-graduando nível doutorado em Otorrinolaringologia da FMUSP.

${ }^{4}$ Professor associado da FMUSP.

Disciplina de Clínica O torrinolaringológica do HCFMUSP - Serviço do Professor Aroldo Miniti

Endereço para correspondência: Dra Roseli Saraiva Moreira Bittar

Av. Dr. Enéas de Carvalho Aguiar n 255, $6^{\circ}$ andar, ICHC; SP - SP - 05403-000

Artigo recebido em 01 de abril de 2002. Artigo aceito em 05 de maio de 2002. 


\section{INTRODUÇÃO}

Entender os distúrbios do equilíbrio corporal como a limitação de um dos sistemas fundamentais para a sobrevivência do indivíduo ajuda-nos a compreender a importância de sua abordagem rápida e precisa tanto quanto possível. Muitos pacientes limitados no desempenho de funções básicas desenvolvem condicionamentos inadequados, fobias e problemas de ordem emocional, muitas vezes de difícil solução ${ }^{1,2}$.

Muito embora as vestibulopatias na infância não sejam tão raras como se supõe, seu diagnóstico é prejudicado pela diversidade de sintomas que as apresentam na criança, por vezes, muito diferentes do indivíduo adulto ${ }^{3}$. Além dessa dificuldade, as crianças não entendem a tontura como um "sintoma anormal", por não saber ao certo o que sentem, e quanto mais novas, maior a dificuldade porque não apresentam ainda 0 domínio da linguagem ${ }^{4,5}$. Como manifestação de desconforto, muitas vezes as crianças choram e em busca de apoio, procuram se agarrar à mãe ou a algum objeto mais próximo, comportamento interpretado com manifestação de dor, crise histérica ou birra³.

$\mathrm{Na}$ grande maioria dos casos, os problemas vestibulares na criança são decorrentes de alterações funcionais relativos à imaturidade do sistema e, portanto, tendem a ser auto-limitados ${ }^{3,6}$. Esse é o principal motivo pelo qual alguns autores acham desnecessária a abordagem clínica da patologia, exceção feita às convulsões e à otite secretora7. Em nossa experiência clínica, entretanto, observamos que tanto quanto o adulto, a criança sofre repercussões dos distúrbios vestibulares em sua vida diária, apresentando comprometimento cognitivo e isolamento social que influenciam direta e negativamente em seu desenvolvimento ${ }^{3,6}$.

Embora o uso de drogas por via oral tenha sido até há pouco tempo o tratamento de eleição, seu uso pode ser necessário por longo período de tempo e, não raro, observamos a ocorrência de efeitos colaterais como sonolência e diminuição de atenção, altamente indesejáveis nesse período crítico da formação intelectual da vida ${ }^{6}$. Em qualquer fase da vida o tratamento etiológico é sempre a melhor opção de tratamento da tontura, seguida pelos métodos que estimulem a compensação central, ficando a medicação como o último recurso a ser utilizado na expectativa de melhorar o quadro clínico do paciente ${ }^{8,9}$.

Baseados em nossos bons resultados com adultos ${ }^{10} \mathrm{e}$ sabendo que as vestibulopatias na infância são em sua grande maioria de ordem funcional, resolvemos tratar essas crianças através da Reabilitação Vestibular. Apresentamos aqui nossos resultados preliminares.

\section{MATERIAL E MÉTODO}

Nossa amostra compreende um grupo de 24 crianças com idade variando entre 4 e 15 anos (média = 8,6 anos; $\mathrm{dp}=3,09$ anos) que apresentavam vestibulopatias de origem periférica, associadas ou não a sintomas de origem central, atendidas durante os anos de 1998 a 2001.

0 protocolo de tratamento instituído foi previamente aprovado pela Comissão de Ética e para início do estudo foi solicitada prévia autorização escrita dos pais ou responsáveis pela criança. Para ser incluída no protocolo de tratamento, a criança deveria apresentar otoscopia e audiometria normais e queixa de tonturas e/ ou enjôo do movimento, associados ou não à cefaléia. Foram excluídas da amostra as crianças que possuíam doenças degenerativas ou tumorais do SNC e aquelas que apresentavam vestibulopatias de origem metabólica e responderam satisfatoriamente ao tratamento clínico.

o grupo foi avaliado pelo mesmo grupo de otoneurologistas do Departamento de 0 torrinolaringologia do Hospital das Clínicas da Faculdade de Medicina da USP, que seguem o mesmo critério para avaliação e diagnóstico em todos os casos. Foi realizada anamnese cuidadosa, exames otorrinolaringológico e neurológico completos, que incluíram o eletroencefalograma quando necessário.

Para o diagnóstico da patologia, foram realizados testes audiométricos e vestibulares. As provas de função vestibular incluíram a eletronistagmografia e a prova rotatória pendular decrescente (PRPD), que foram realizados isoladamente ou em conjunto, na dependência da colaboração e idade da criança $^{11}$. Foram incluídas no estudo as crianças que apresentavam predomínio labiríntico e/ou preponderância direcional à prova calórica ou PRPD ou ainda aquelas que apresentavam histórico altamente sugestivo, mesmo que apresentassem exames vestibulares normais.

0 método utilizado para o tratamento com reabilitação vestibular foi a técnica descrita primariamente por Caw thorne $\&$ Cooksey, modificada e adaptada para nossa população ${ }^{12}$. A orientação e exercícios recomendados às crianças foram os mesmos que fazem parte de nossa rotina de atendimento para adultos ${ }^{10}$. Foram realizadas quatro sessões de acompanhamento $10,15 \circ, 30$ e e $60^{\circ}$ dias.

Durante a primeira avaliação as crianças foram submetidas a um questionário inicial onde eram quantificados o número e duração das crises de tonturas ou episódios de cinetose. As crianças e os responsáveis foram esclarecidos quanto à origem de seus sintomas e então ensinados os exercícios que incluíram movimentos de olhos e cabeça, fixação do olhar, marcha e jogos com bola. Os exercícios deveriam ser realizados diariamente, duas vezes ao dia por dez vezes cada um, durante 60 dias.

Nas duas entrevistas intermediárias de avaliação, as dificuldades apresentadas durante o período de tratamento foram analisadas e novos exercícios foram adicionados ou corrigidos quando necessário, individualizando o tratamento para cada criança.

Ao final do segundo mês, as crianças foram submetidas ao mesmo questionário inicial e os resultados foram assim classificados: 
MELHORA TOTAL: Ausência de sintomas após o tratamento.

SEM MELHORA: Sem modificação do quadro inicial referido pela mãe.

MELHORA PARCIAL: Diminuição da intensidade e/ ou freqüência das queixas iniciais, sem no entanto chegar ao estado assintomático.

As crianças que ainda apresentavam sintomas foram solicitadas a realizar os exercícios por mais um mês, mantendo-se o esquema de tratamento e adicionando novos exercícios quando necessário.

As crianças foram então classificadas segundo o índice de melhora após o tratamento instituído e comparadas ao grupo total de pacientes submetidos ao programa de RV no ambulatório de RV do HCFMUSP durante o mesmo período. A análise estatística incluiu métodos descritivos e para estudar a distribuição das freqüências foi utilizado o teste do quiquadrado com nível de significância de 5\%.

\section{RESULTADOS}

Iniciaram o tratamento 24 crianças e duas 0 abandonaram durante 0 estudo. Uma criança que havia apresentado melhora total apresentou recidiva das crises 6 meses após o término do programa. As que finalizaram 0 tratamento são relacionadas na Tabela 1.

Os resultados obtidos no grupo de crianças e no grupo total de pacientes submetidos à RV no ambulatório do HCFMUSP durante o mesmo período de observação podem ser visualizados na Tabela 2.
A distribuição das 22 crianças submetidas à RV foi significativamente diferente da população total $(p<0,02)$. As crianças apresentam melhores respostas ao programa quando comparadas ao grupo total de pacientes submetidos à RV, que inclui os pacientes adultos.

\section{DISCUSSÃO}

Como colocado anteriormente, as disfunções do equilíbrio na criança são geralmente dependentes de processos funcionais e segundo nossa casuística, $9 \%$ dessas crianças não apresentam alterações dos exames vestibulares ${ }^{3}$, motivo pelo qual a história clínica sugestiva foi considerada critério de inclusão neste estudo, mesmo na presença de exames normais.

Quando iniciamos nosso trabalho com crianças, esperávamos que elas apresentassem uma certa resistência aos exercícios habitualmente utilizados com os adultos, por serem repetitivos e portanto, cansativos. Essa idéia não se confirmou e as crianças responderam muito bem ao método clássico, realizando corretamente os exercícios. Apenas uma das crianças demonstrou desinteresse à repetição dos movimentos e para ela foram colocadas novas tarefas na forma de brincadeiras infantis, como a cambalhota, pular amarelinha, corrupio e andar descalço em colchonete.

Observamos que a recuperação da criança é mais efetiva em relação ao adulto, demonstrando a eficácia da plasticidade neuronal durante a infância ${ }^{11,13}$. Elas respondem significativamente melhor aos exercícios, e é nossa impressão pessoal que a melhora acontece mais rapidamente também,

Tabela 1. Distribuição das crianças segundo sexo, idade, queixa, duração e resultado do tratamento.

\begin{tabular}{|c|c|c|c|c|c|c|c|}
\hline & Nome & Sexo & Idade & Queixa & $\begin{array}{c}\text { Duração do } \\
\text { Tratamento } \\
\text { (meses) }\end{array}$ & Evolução & Recidiva \\
\hline 1 & BSF & $\mathrm{F}$ & 6 & cinetose & 2 & total & - \\
\hline 2 & MNN & $\mathrm{F}$ & 5 & cinetose+ tontura & 2 & parcial & - \\
\hline 3 & $\mathrm{~J} A B$ & $M$ & 10 & cinetose & 2 & total & - \\
\hline 4 & FB & $\mathrm{F}$ & 9 & cinetose+tontura & 3 & total & - \\
\hline 5 & DARS & $M$ & 8 & tontura & 2 & total & - \\
\hline 6 & DGS & $\mathrm{F}$ & 13 & cefaléia + tontura & 3 & parcial & - \\
\hline 7 & AJ $C$ & $\mathrm{~F}$ & 11 & cefaléia+tontura & 2 & total & - \\
\hline 8 & J BS & $\mathrm{F}$ & 15 & cefaléia + tontura & 2 & total & - \\
\hline 9 & PEGL & M & 10 & cefaléia + tontura & 2 & total & - \\
\hline 10 & $\mathrm{ABO}$ & $\mathrm{F}$ & 7 & cinetose+tontura & 2 & total & - \\
\hline 11 & RSS & $M$ & 9 & cefaléia + tontura & 2 & total & - \\
\hline 12 & MED & $\mathrm{F}$ & 11 & tontura & 3 & parcial & - \\
\hline 13 & DAC & $\mathrm{F}$ & 11 & cefaléia + tontura & 2 & total & - \\
\hline 14 & TPT & $\mathrm{F}$ & 9 & cefaléia + tontura & 2 & total & - \\
\hline 15 & DL & $\mathrm{F}$ & 4 & cinetose & 2 & total & - \\
\hline 16 & DS & $\mathrm{F}$ & 5 & cinetose & 2 & total & - \\
\hline 17 & FRZ & M & 4 & tontura & 2 & total & + \\
\hline 18 & CMR & $\mathrm{F}$ & 14 & cinetose & 3 & total & - \\
\hline 19 & EXL & $\mathrm{F}$ & 8 & tontura & 3 & total & - \\
\hline 20 & LFS & $\mathrm{F}$ & 6 & tontura & 2 & total & - \\
\hline 21 & APRS & $\mathrm{F}$ & 7 & cefaléia + tontura & 2 & parcial & - \\
\hline 22 & LCS & $M$ & 7 & cinetose+tontura & 2 & total & - \\
\hline
\end{tabular}


Tabela 2. Distribuição da população submetida à RV, segundo o índice de melhora ao final do programa.

\begin{tabular}{ccccc}
\hline & $\begin{array}{c}\text { Melhora } \\
\text { Total }\end{array}$ & $\begin{array}{c}\text { Melhora } \\
\text { Parcial }\end{array}$ & $\begin{array}{c}\text { Sem } \\
\text { Melhora }\end{array}$ & Total \\
\hline $\begin{array}{c}\text { CRIANÇA } \\
\mathrm{n}=22\end{array}$ & $18(81,8 \%)$ & $4(18,2 \%)$ & - & $22(100 \%)$ \\
$\begin{array}{c}\text { TOTAL } \\
\mathrm{n}=177\end{array}$ & $95(53,67 \%)$ & $44(24,85 \%)$ & $38(21,46 \%)$ & $177(100 \%)$ \\
\hline
\end{tabular}

podendo ser observada ao redor do primeiro mês de tratamento, enquanto que essa observação é feita no adulto, em média, após dois meses de tratamento.

A observação de recidiva em uma criança que havia apresentado melhora total após o programa é um fato que permanece sem explicação. Sabemos que para que seja mantido o resultado obtido com o trabalho de RV, é preciso que o paciente possua vida ativa, pratique esportes e brincadeiras que estimulem as aferências e eferências responsáveis pelo equilíbrio corporal ${ }^{14}$. Qualquer atividade física é benéfica para a criança, mas em nossa opinião, o judô e o balé são atividades altamente indicadas porque trabalham o equilíbrio corporal diretamente, desenvolvendo a postura e a coordenação.

Uma das queixas mais freqüentes nessas crianças vestibulopatas é a cinetose, e portanto, a limitação em participar de brincadeiras que envolvam o movimento, principalmente a rotação, elemento básico nos brinquedos de parques de diversões. Além disso, o movimento em transportes coletivos e viagens de carro em estradas longas e sinuosas é outro fator desencadeante de enjôos e vômitos. Tal fato é freqüentemente relatado pela mãe, que fica assustada com a palidez que a criança apresenta e sua apatia, imaginando tratar-se de um desmaio. As crianças, por outro lado, sentem-se envergonhadas por vomitar durante a crise, perto de pessoas estranhas que a ficam observando. Por tal motivo, esse foi um sintoma muito bem investigado em nossas crianças e serviu como parâmetro de avaliação da eficácia do tratamento. O utra solicitação que eventualmente fazemos à mãe para concluir se a terapia foi efetiva, é que ela leve a criança ao parque infantil, quando há relato de crises durante as brincadeiras que envolvem a rotação. $\mathrm{Na}$ grande maioria das vezes, após o tratamento a criança brinca normalmente, sem apresentar vômitos, enjôo ou tontura. Nossos resultados confirmam achados anteriores de melhora significativa da cinetose com RV ${ }^{15}$. Todas as crianças que apresentavam esse sintoma como queixa única apresentaram melhora total.

Em nosso grupo de crianças avaliamos a RV isoladamente, porém nada impede que seja utilizado medicamento em conjunto. Temos observado boa resposta das crianças a quatro drogas que consideramos de eleição para o tratamento do pequeno paciente: Ginkgo Biloba, cinarizina, dimenidrato e clonazepam. Dentre essas drogas, entretanto, o Ginkgo Biloba nos parece a melhor opção de uso durante a RV, pois as outras drogas apresentam efeito sedante do SNC, efeito altamente indesejável durante um programa de ativação da plasticidade neuronal.

\section{CONCLUSÕES}

Acreditamos que a RV é um método altamente recomendável às crianças vestibulopatas, desde que anteriormente investigadas e corretamente diagnosticadas. Nos casos de cinetose pura, a RV é sem duvida o tratamento de primeira escolha.

\section{REFERÊNCIASBIBLIOGRÁFICAS}

1. Staab JP. Diagnosis and treatment of psychologic symptoms and psychiatric disorders in patients with dizziness and imbalance. Otolaryngol Clin North Am 2000;33(3):617-35.

2. Pedalini MEB, Bittar RSM, Formigoni LG, Cruz OLM, Bento RF, Miniti. Reabilitação vestibular como tratamento da tontura: experiência com 116 casos. Arquivos da Fundação Otorrinolaringologia $1999 ; 3(2): 74-8$.

3. Formigoni LG, Medeiros IRT, Santoro PP, Bittar RSM, Bottino MA. Avaliação clínica das vestibulopatias na infância. Rev Bras ORL 1999;65(1):78-82.

4. Fried MP. The evaluation of dizziness in children. Laryngoscope 1980;90:1548:60.

5. Eeg-Olofsson O, Odvkvist L,Lindskog U, Andersson B. Benign paroxismal vertigo in childhood. Acta Otolaryngol 1982;93(34):283-9.

6. Ganança MM, Caovilla HH, Munhoz MSL, Munhoz ML, Ganança FF. Tratamento da vertigem na criança. Pediatria Moderna 1997;33(1):7-22.

7. Blayney AW, Colmana BH. Dizziness in childhood. Clin Otolaryngol 1984;9(2):77-85

8. Bittar RSM, Pedalini MEB, Formigoni LG. Reabilitação vestibular: Uma arma poderosa no auxílio a pacientes portadores de tontura. Rev Bras Otorrinolaringol 1999;65(3):266-9.

9. Medeiros I, Pedalini ME, Bittar RSM, Formigoni LG. Scientific Posters: Vestibular Rehabilitation in Children with Vestibular Disorders Otolaryngol Head Neck Surg 2001;125(2), Special Issue: S143.

10. Pedalini MEB, Bittar RSM. Reabilitação vestibular: Uma proposta de trabalho. PRÓ-FONO 1999;11(1):140-4.

11. Fife TD, Tusa RJ, Furman JM, Zee DS, Frohman E, Baloh RW, Hain T, Goebel J, Demer J, Eviatar L. Assessment: Vestibular testing techniques in adults and children: Report of the Therapeutics and Technology Assessment Subcommittee of the American Academy of Neurology. Neurology 2000;55(10):1431-41.

12. Cawthorne TE. The physiological basis of head exercises. J Chart Soc Physio Ther; 1944;106-107.

13. Hirabaiashi S, Iwasaki. Developmental perspective of sensory organization on postural control. Brain \&Development 1995;17:111-3.

14. McCabe BF. Labyrinthine exercises in the treatment of diseases characterised by vertigo: their physiologic basis and methodology. Laryngoscope 1970;80:1429-53.

15. Barbosa MSM, Godoy NP, Campos MI, Suzuki FA, Ganança MM. Da estimulação optocinética como auxiliar na compensação labiríntica em síndromes vestibulares periféricas. Acta AWHO 1993;12(1):29-32. 